\title{
Conflito interpessoal entre brasileiros e entre brasileiros e estrangeiros em empresas multinacionais de Manaus, AM
}

\author{
Gizelly de Carvalho Martins e Agnaldo Garcia \\ Universidade Federal do Espírito Santo (Vitória, ES)
}

\begin{abstract}
A globalização tem permitido o contato entre trabalhadores de diferentes países e culturas. O objetivo desta pesquisa foi investigar conflitos interpessoais envolvendo trabalhadores brasileiros e estrangeiros no setor eletroeletrônico da Zona Franca de Manaus. Quatorze trabalhadores brasileiros foram entrevistados acerca de conflitos com outros brasileiros e estrangeiros no local de trabalho quanto aos fatores desencadeadores do conflito, o episódio de conflito e suas consequências. Os fatores desencadeadores de conflito foram organizados em sete grupos: (a) Produtividade e eficiência; (b) Metodologia do trabalho e planejamento; (c) Hierarquia e comando ou liderança; (d) Problemas da empresa ou institucionais; (e) Comunicação e relacionamento interpessoal; (f) Questões éticas ou morais; (g) Diferenças culturais e educação diferenciada. Os conflitos se manifestaram mais como características de um relacionamento no tempo do que como interações pontuais e apresentaram consequências positivas e negativas de acordo com os participantes. Diferenças culturais foram reconhecidas no relacionamento com estrangeiros e também com outros brasileiros. Comparados aos conflitos interpessoais entre brasileiros, os conflitos com estrangeiros mostraram maior diversidade e intensidade, mas um desfecho mais positivo. Pode-se concluir que diferenças culturais afetam conflitos interpessoais, estando presentes no relacionamento entre brasileiros e estrangeiros e entre brasileiros de diferentes origens.
\end{abstract}

Palavras-chave: Conflito interpessoal, Diferenças culturais, Empresas multinacionais.

Interpersonal conflict between Brazilians and between Brazilians and foreign workers in multinational companies in Manaus, AM

Globalization has allowed the contact among workers from different countries and cultures. The objective of this study was to investigate interpersonal conflicts involving Brazilian and foreign workers in the sector of electrical and electronic appliances, in the Free Zone of Manaus. Fourteen Brazilian workers were interviewed about conflicts with other Brazilians and foreigners in the workplace, including triggering factors of conflict, the episode of conflict and its consequences. The triggering factors of conflict were organized into seven groups: (a) Productivity and efficiency (b) Work methodology and planning, (c) Hierarchy, command and leadership, (d) Institutional or company problems, (e) Communication and interpersonal relationships, (f) Ethical and moral issues, (g) Cultural and educational differences. The conflict was typically part of an ongoing relationship and not only a specific interaction and showed positive and negative consequences according to the participants. Cultural differences were recognized in the relationship with foreigners and with other Brazilians. Conflicts with foreigners showed greater diversity and intensity, but more positive outcomes when compared with interpersonal conflicts among Brazilians. It may be concluded that cultural differences affect interpersonal conflicts but these differences are present not only in the relationship between Brazilians and foreigners but also among Brazilians of different origins.

Keywords: Interpersonal conflict, Cultural differences, Multinational companies.

$\mathrm{O}$ relacionamento interpessoal é fundamental para o funcionamento das empresas. Com a globalização da economia, cada vez mais pessoas de países e culturas diferenciadas entram em contato, por vezes no mesmo ambiente de trabalho, podendo dar origem a conflitos interculturais. No Brasil, a cidade de Manaus fornece um exemplo particularmente relevante devido à presença de empresas multinacionais que permitem o contato entre brasileiros e estrangeiros no local de trabalho. Esta pesquisa buscou investigar conflitos de natureza interpessoal de trabalhadores brasileiros com estrangeiros e com outros brasileiros no setor eletroeletrônico da Zona Franca de Manaus, do ponto de vista de trabalhadores brasileiros. 


\section{Relacionamento interpessoal e conflito intercultural no local de trabalho}

De acordo com Garcia (2005), o relacionamento em ambiente organizacional representa uma proporção muito pequena dos estudos publicados em revistas internacionais especializadas em relacionamento interpessoal. A importância deste para as organizações, contudo, tem sido reconhecida por diferentes autores. Sato (1999), por exemplo, ressalta que o que faz a organização é a interação entre as pessoas. A organização sempre será aquilo que as pessoas nela envolvidas fazem e/ou desenvolvem. Os processos sociais envolvidos apresentam dois aspectos principais: a harmonia (devido a interesses semelhantes e comuns e compartilhados) e o conflito (interesses diferentes e contraditórios).

Com o avanço de uma economia globalizada, torna-se cada vez mais frequente o contato entre trabalhadores de diferentes países e culturas. Como consequência surgem conflitos interculturais entre tradições culturais ligadas a diferentes nações, no local de trabalho. Conhecer a natureza e possíveis formas de lidar com esses conflitos é uma contribuição para a administração e a psicologia, especialmente para os estudos sobre relacionamento interpessoal.

Para Hamdorf (2003), o sucesso das empresas com a globalização da economia também depende de negociações com parceiros de outras culturas e do trabalho de equipes multinacionais, criando novos desafios para empresas, empregados e departamentos de recursos humanos. Há a necessidade da gestão de diversidade, de diferenças culturais nos valores e normas de comportamento. Os encontros interculturais facilmente dão origem a malentendidos e comportamentos involuntariamente ofensivos, resultando em conflitos interculturais. As pessoas tendem a interpretar as ações do outro segundo suas próprias normas culturais. Esses conflitos geram custos para as empresas e afetam o bem-estar e produtividade dos trabalhadores, gerando estresse, perda de autoconfiança, segurança na própria competência e o aumento de preconceitos e estereótipos.

Segundo Choe (2001), indivíduos de comunidades culturais contrastantes apresentam diferenças nos valores, suposições, expectativas, hábitos verbais e não verbais e scripts de interação que podem gerar conflitos, vistos como a percepção de incompatibilidade de valores, normas, processos ou metas entre duas partes sobre identidade cultural, relacional e/ou questões materiais. O conflito intercultural muitas vezes começa devido a diferentes expectativas quanto ao comportamento adequado ou inadequado em uma interação.

Para Sanchez-Burks, Blount e Bartel (2006), manter interações interpessoais fluidas nas organizações é mais difícil quando o trabalho implica relações interculturais. Preconceito e desconfiança são obstáculos comuns à interação social produtiva, tornando difícil para indivíduos de diferentes culturas trocar e integrar suas ideias, esforços e recursos. Ao mesmo tempo, interações interculturais podem promover a criatividade, bem como melhorar a resolução de problemas e o desempenho individual e grupal.

Identificar os empecilhos para boas interações interculturais tornou-se uma questão central para estudiosos da questão. Ting-Toomey e Oetzel (2001) ressaltam que nos EUA imigrantes e grupos minoritários representam cerca de 30\% da força de trabalho, tornando essencial a administração de conflitos interculturais. Afirmam que a maioria dos conflitos no local de trabalho deve-se ao desconhecimento ou compreensão distorcida da cultura do outro.

Para Sanchez-Burks, Nisbett e Ybarra (2000), etnocentrismo, preconceitos e malentendidos frequentemente acompanham o contato intercultural. No trabalho, este está associado a conflitos, concorrência intergrupal negativa e absenteísmo. As diferenças culturais em estilo relacional afetam o grupo, gerando diferentes hipóteses sobre padrões adequados de interação. Sanchez-Burks e Mor-Barak (2004) afirmam que pessoas de culturas diferentes 
trazem diferentes expectativas, crenças e suposições sobre formas adequadas de se relacionar e se comunicar no trabalho. É necessário compreender a diversidade cultural e como ela influencia a comunicação e os esquemas ou estilos relacionais. Entre as diferenças culturais, apontam a ênfase no relacionamento ou na tarefa e o emprego de comunicação direta ou indireta. Diferenças culturais aumentam as possibilidades de incompreensões e conflitos.

Ting-Toomey e Oetzel (2001) concordam que conflitos interculturais frequentemente se iniciam com diferentes expectativas quanto ao comportamento apropriado e inapropriado em um conflito. Quando pessoas de diferentes culturas entram em conflito, elas frequentemente têm expectativas diferentes de como lidar com ele, desde a definição do problema referente ao conflito, seu evento disparador e como veem os alvos para a resolução. Os autores definem cultura como "um sistema aprendido de significados que promovem um sentido particular de identidade e comunidade compartilhadas entre os membros do grupo" (p. 9). Ou, de forma mais precisa, como "um sistema de significados aprendidos que consiste de padrões de tradições, crenças, valores, normas, e símbolos que são passados de uma geração para a seguinte e são compartilhados em graus variáveis pelos membros interagindo em uma comunidade" (Ting-Toomey, 1999, p. 10).

Outros autores investigaram aspectos mais específicos dos conflitos interculturais no local de trabalho. Por exemplo, Spicer (1997) tratou de conflitos em ambientes multinacionais na Rússia, reconhecendo a transferência de conhecimentos culturalmente específicos como a principal fonte de conflito interpessoal. Chan e Goto (2003) analisaram como a percepção social de distância afeta trabalhadores de Hong Kong quanto às percepções da situação de conflito, suas escolhas e procedimentos de resolução. Euwema e Van Emmerik (2007) exploraram as relações entre as competências interculturais e conflitos interpessoais dentro de um contexto intercultural, apontando para a importância da posição competitiva ou cooperativa dos componentes. Oetzel, Dhar e Kirschbaum (2007) analisaram e sintetizaram as tendências de investigação sobre conflito intercultural no contexto interpessoal, organizacional, comunitário e internacional, buscando uma abordagem integrada. Propõem o quadro social ecológico, reconhecendo vários níveis que permitiriam a investigação e a integração dos diferentes contextos. Parte da literatura refere-se a estilos de resolução de conflitos em diferentes situações ou países (Boonsathorn, 2007; Kim, Wang, Kondo \& Kim, 2007; Posthuma, White, Dworkin, Yánez \& Swift, 2006; Tinsley e Brett, 2001).

Kim, Wang, Kondo e Kim (2007) examinaram como chineses, japoneses e coreanos resolvem um conflito interpessoal com seus supervisores e como fatores culturais explicam as diferenças nos estilos de administração de conflito. Os coreanos, comparados com os chineses e japoneses, tinham maior probabilidade de usar um estilo intermediário. Os japoneses, quando comparados com chineses e coreanos, tinham menor probabilidade de tentar dominar ou constranger os supervisores. As diferenças nacionais foram parcialmente explicadas pela ênfase no alvo (a própria pessoa ou o grupo). Posthuma, White, Dworkin, Yánez e Swift (2006) encontraram estilos de resolução de conflito entre colegas de trabalho diferentes no México e nos EUA. A nacionalidade e a proximidade da fronteira influenciaram o grau de identidade cultural e estilos de resolução de conflito preferidos nos dois grupos. Mexicanos geralmente disputavam mais e cediam menos aos colegas que os americanos. Contudo, os mexicanos também tinham maior probabilidade de responder à disputa de colegas acomodando ou se comprometendo com o colega.

Brew e Cairns (2004) investigaram a influência da cultura e das limitações situacionais na escolha de estilos diretos ou indiretos nos conflitos interculturais no local de trabalho. As pessoas em nações individualistas preferem a comunicação direta, explícita como estratégia de gestão de conflitos, enquanto nações coletivistas prefeririam estratégias de comunicação contextual. No entanto, em um contexto multicultural de trabalho, somente a orientação cultural não pode predizer a escolha da estratégia, mas limitações situacionais podem contribuir. 
No Brasil, a convivência intercultural nas organizações foi investigada por Freitas (2000, 2005), incluindo a realidade de estrangeiros no Brasil (Freitas, 2000) e a de brasileiros expatriados e seus cônjuges no exterior (Freitas, 2005).

Freitas (2008) reconhece o fato de a "convivência intercultural estar assumindo uma posição cada vez mais importante na vida social e organizacional" (Freitas, 2008, p. 80) e destaca a "construção de uma mentalidade intercultural como um ideal" (Freitas, 2008, p. 81). Segundo Freitas (2008), do ponto de vista das relações humanas, essa convivência pode "favorecer o desenvolvimento crescente de uma maior sensibilidade, tolerância e respeito pela vida de pessoas, grupos e sociedades de origens distintas, inclusive no universo organizacional" (Freitas, 2008, p. 81). Essa convivência traz consigo um grande potencial, mas também alguns riscos para as organizações, como a "elevação de conflitos internos" (Freitas, 2009, p. 262).

A autora (Freitas, 2008), ao mesmo tempo que reconhece os avanços na sociedade internacional com a convivência intercultural, também reconhece as dificuldades e conflitos gerados por essa convivência, partindo do pressuposto de que "o reconhecimento do outro diferente é um avanço na melhoria da convivência de pessoas, sociedades e organizações, visto que o seu estudo - sem negar o potencial de conflitos entre as partes - favorece o respeito mútuo, a redução dos estereótipos, das incompreensões e das dificuldades na interação entre portadores de diferentes culturas" (Freitas, 2008, p. 81).

Freitas (2008) aponta como consequências imediatas do aumento do contato intercultural no mundo organizacional "a formação de um ambiente de trabalho cada vez mais qualificado, heterogêneo e com maior potencial de conflitos e exclusão" (Freitas, 2008, p. 83). Isso traz consigo "a urgência no desenvolvimento de maiores competências comunicativas e de negociação" (Freitas, 2008, p. 83), além da "necessidade de habilidades para a coordenação de equipes multiculturais e multidisciplinares" (Freitas, 2008, p. 83).

Em outro trabalho, afirma que "se, por um lado, acreditamos no enorme potencial da melhoria na convivência humana por meio dos encontros interculturais provocados por uma mobilidade qualificada; por outro lado, é lícito supor que dela podem decorrer alguns perigos ou efeitos negativos" (Freitas, 2009, p. 262).

Em suma, a convivência intercultural mostra-se de grande importância para desenvolvimento social e organizacional internacional; contudo, não podem ser deixados de lado os riscos de conflito associados a esses contatos.

\section{Relações de conflito entre supervisores e subordinados}

Rahim (1992) refere-se a diferentes níveis de análise do conflito organizacional. Entre os conflitos intraorganizacionais insere o conflito interpessoal ou diádico, entre dois ou mais membros da organização com o mesmo ou diferentes níveis hierárquicos. Os estudos sobre conflito superior-subordinado se referem a esse tipo.

Nas organizações, as pessoas não possuem idêntico poder ou autoridade, o que pode resultar em conflito (McIntyre, 1991). A posição hierárquica apresenta diferenças de poder e status desafiando o relacionamento líder-subordinado (Hogan, Curphy \& Hogan, 1994). Segundo McIntyre (2007), o papel de chefe, colega ou subordinado poderá condicionar o estilo para lidar com o conflito, e mesmo a utilização de termos como "chefe" e "subordinado" poderá criar certo conflito numa sociedade "democrática" com ideais de igualdade.

Segundo Rahim (1992), quando os chefes utilizam um estilo de dominação com seus subordinados, estes tendem a empregar o estilo de evitamento. Quando os chefes procuram 
"controlar" os subordinados, estes resistem, gerando conflito. Em termos de conflito, pode-se dizer que este existe em boa parte devido à existência de hierarquias (Rahim, 1986).

Nos estudos de Rahim (1986), Rahim e Buntzman (1989), McIntyre (1991) e Holt e DeVore (2005) foram percebidas diferenças significativas nos estilos da gestão de conflito utilizados quer pelos chefes, pelos subordinados, quer pelos colegas, concluindo-se que o relacionamento hierárquico condicionava o estilo utilizado pela pessoa envolvida no conflito. Rahim (1986) observou que gestores utilizavam predominantemente o estilo de integração com os subordinados, de acomodação com os chefes e de concessão mútua com os colegas. McIntyre (1991) observou o mesmo comportamento, apesar de os subordinados tenderem a perceber seus chefes empregando o estilo de evitamento com eles.

Segundo Xin e Pelled (2003), apesar de um volume expressivo de pesquisas sobre conflito no local de trabalho, faltam investigações sobre o conflito entre pessoas em diferentes níveis hierárquicos. Os estudos têm contribuído mais para a compreensão do conflito entre pares do que entre pessoas em diferentes níveis de uma organização. Segundo os autores, estudos do conflito no contexto supervisor-subordinado têm focado amplamente conflito de papéis (por exemplo, Schaubroeck, Ganster, Sime \& Ditman, 1993), situações em que um subordinado encara expectativas inconsistentes ou contraditórias de trabalho. Afirmam haver uma falta de atenção a conflitos interpessoais - por exemplo, disputas, desacordos, ou enfrentamentos - que possam caracterizar as interações entre supervisores e subordinados.

Schaubroeck, Ganster, Sime e Ditman (1993) avaliaram um programa de intervenção para altos níveis de ambiguidade de papéis entre gerentes intermediários e seus subordinados nos serviços administrativos de uma universidade. Reorganizações da divisão criaram considerável turbulência nos papéis individuais e nas relações entre os departamentos, resultando em estresse e outros problemas de saúde. Após um estudo de dois anos e meio, partiu-se para uma intervenção para esclarecimento de papéis indicando as responsabilidades dos gerentes e departamentos, que terminou com sessões individuais de negociação de papéis entre gerentes e cada subordinado, resultando em redução da percepção de ambiguidade de papel, mas com impacto limitado nos sintomas da saúde dos empregados ou faltas por problemas de saúde.

Xin e Pelled (2003) investigaram a estrutura do conflito em 72 díades verticais de supervisores-subordinados e os efeitos do conflito sobre o comportamento de liderança percebido, encontrando dois tipos de conflito: o puramente emocional e o misto, uma combinação de conflito de tarefa e emocional. Ambos estavam associados negativamente com as percepções do comportamento de liderança dos supervisores. A estrutura do conflito nesse estudo diferiu da tradicional dicotomia tarefa-emoção encontrada em estudos de conflito com pares (Amason, 1996; Jehn, 1995; Pelled, Eisenhardt \& Xin, 1999). Os autores (Xin \& Pelled, 2003) explicam a estrutura diferenciada do conflito em função de uma "bagagem emocional" extra que acompanha conflitos de tarefa entre supervisores e subordinados. Aparentemente, seria difícil para os supervisores aceitar críticas a tarefas ou desafios de subordinados sem sentir emoções fortes, gerando ansiedade e desconforto. Além disso, podem ameaçar sua posição social. Possivelmente, os sentimentos negativos que caracterizam o conflito vertical puramente emocional tornam difícil para os subordinados respeitar seus supervisores e avaliá-los favoravelmente. Assim, o conflito emocional entre supervisores e subordinados pode ser tão disfuncional quanto o conflito entre pares (Amason, 1996; Eisenhardt, Kahwajy \& Bourgeois, 1997; Jehn, 1995). 


\section{Manaus, a Zona Franca e o setor eletroeletrônico}

Segundo Nogueira, Sanson e Pessoa (2007), a implementação da Zona Franca, a partir de 1967, é um momento econômico e social de destaque para Manaus, influenciando o crescimento urbano da cidade e atraindo migrantes do interior do Estado e do resto do País. Em termos populacionais, Santos (2002) destaca que a imigração de estrangeiros acompanhou o desenvolvimento de Manaus. Na década de 1980, 81,23\% dos estrangeiros do Estado residiam em Manaus, onde se concentra o capital econômico e financeiro do Estado. $\mathrm{O}$ autor indica a imigração, a partir da década de 1960, de pessoas oriundas de países vizinhos, como o Peru, Colômbia, Venezuela, Guiana Inglesa e Bolívia, além dos Estados Unidos, Japão e China. Essas novas correntes indicam mudanças econômicas mundiais, em que os EUA e Japão e Coreia (tigres asiáticos), na década de 1980, vão redimensionar as economias e o capital do mundo globalizado. Com a Zona Franca, a população de Manaus atinge cerca de 1,6 milhão de pessoas ao final de 2002 , concentrando $53 \%$ da população estadual, sendo responsável por mais de $90 \%$ da economia e da arrecadação estadual (Loureiro, 2003).

Segundo Coutinho Neto (2004), as empresas do Polo Eletroeletrônico foram as primeiras a ocupar a Zona Franca de Manaus (ZFM) e representam um dos setores mais importantes da economia da cidade. Segundo Sics (2002), o faturamento dos setores de eletrônica de consumo e de bens de informática da ZFM em 2001 foi de cerca de US \$ 4,9 bilhões. Segundo Loureiro (2003), o segmento eletroeletrônico, com alta produtividade e significativo domínio de tecnologias, é responsável por metade do faturamento industrial. As empresas mais importantes em nível internacional no campo da produção de bens eletroeletrônicos estão de alguma maneira representadas na ZFM.

O polo eletroeletrônico fabrica televisores, videocassetes, aparelhos de rádio e insumos para estas indústrias (Lyra, 1995). Apesar dos aspectos positivos para o desenvolvimento social e econômico da região, a Zona Franca também tem recebido diversas críticas. Para alguns, ela pode ser vista como momento decisivo para a transição de um projeto de capitalismo nacional para o capitalismo internacional, em que a dinâmica econômica e os centros decisórios estão fora do país (Seráfico \& Seráfico, 2005).

O objetivo da presente pesquisa é descrever e analisar conflitos de natureza interpessoal de trabalhadores brasileiros com estrangeiros e com outros brasileiros no setor eletroeletrônico da Zona Franca de Manaus, com ênfase nos fatores desencadeadores dos conflitos, os episódios de conflito propriamente dito e as consequências pessoais e profissionais do conflito. A presente investigação visa contribuir para um melhor relacionamento entre brasileiros e estrangeiros e brasileiros e brasileiros no ambiente de trabalho, promovendo o bem-estar do trabalhador e a resolução de conflitos nesse ambiente. Ainda visa contribuir para o conhecimento da temática em nosso País em face da escassez de pesquisas sobre o tema do relacionamento intercultural nas empresas, especialmente na região Norte.

Em suma, a literatura tem ressaltado a importância crescente dos conflitos interculturais no local de trabalho e a necessidade de estratégias mais eficientes para lidar com tais conflitos. Três aspectos centrais caracterizam a literatura sobre o tema: (a) o relacionamento interpessoal entre pessoas de diferentes culturas representa uma questão relevante de pesquisa com características e dificuldades próprias; (b) a literatura é predominantemente estrangeira, abordando relacionamentos interculturais interpessoais em outros países, geralmente de uma perspectiva dos gerentes ou administradores dessas empresas; (c) mesmo referindo-se ao mesmo tema de conflito interpessoal intercultural, os trabalhos apresentam diferentes abordagens ou aspectos investigados; (d) o conflito interpessoal de natureza intercultural é uma dificuldade presente no convívio entre trabalhadores de diferentes nacionalidades que merece ser investigado em função do avanço de uma sociedade globalizada. 
A partir da revisão da literatura, a questão do conflito entre pessoas de diferentes culturas nas organizações mostrou-se como um tema contemporâneo e relevante de pesquisa, afetando a possibilidade de construção de uma sociedade internacional marcada pela tolerância e respeito mútuo. A existência e a natureza dos conflitos interculturais no Brasil ainda são pouco exploradas, especialmente do ponto de vista do trabalhador brasileiro. Assim, tanto a coleta de dados quanto a discussão dos resultados foram orientadas no sentido de identificar a natureza desses conflitos. Para identificar as características dos conflitos com estrangeiros, também foram investigados conflitos com outros brasileiros, para indicar possíveis semelhanças e diferenças.

Parte-se do pressuposto de que mapear e identificar os conflitos entre brasileiros e estrangeiros, comparando-os com conflitos com outros brasileiros, represente um primeiro passo para o avanço dos estudos interculturais do conflito interpessoal, com vistas a promover o bem-estar do trabalhador e a busca da resolução desses conflitos.

Para a organização do trabalho foi tomada como base a obra de Hinde (1997), com ênfase em aspectos descritivos, seguidos pela sistematização dos dados e a busca de princípios explicativos. Outro aspecto relevante da obra de Hinde é a consideração de diferentes níveis de complexidade afetando o relacionamento interpessoal, como grupos a sociedade, estrutura sociocultural e ambiente físico. No caso presente, considera-se que seja um fator relevante a dimensão cultural de pertença a diferentes nacionalidades.

\section{Metodologia}

\section{Participantes}

Os participantes foram identificados a partir do contato com o setor de $\mathrm{RH}$ de várias empresas multinacionais de Manaus, de forma aleatória, sem nenhuma empresa foco. Foram entrevistados 14 empregados brasileiros de empresas multinacionais do setor eletroeletrônico de Manaus que estavam trabalhando no momento da entrevista ou que haviam trabalhado nos cinco anos anteriores. Para participar, os funcionários deviam declarar já ter vivido, em algum momento, algum tipo de conflito com estrangeiros e brasileiros no trabalho. Apesar de as instruções mencionarem apenas conflitos com outros brasileiros ou estrangeiros, todos trataram de conflitos com um chefe ou supervisor.

Os 14 brasileiros entrevistados tinham entre 21 e 50 anos. Cinco tinham entre 21 e 30 anos, oito entre 31 e 40 anos e um entre 41e 50 anos. Onze eram naturais de Manaus, um de Brasília, um de São Paulo e um do Pará. Dez eram do sexo masculino e quatro do sexo feminino. Quanto à escolaridade, um tinha o curso superior incompleto e 13 possuíam curso superior completo. Destes, 11 também tinham curso de especialização completo e dois um curso de especialização incompleto. Na empresa, três tinham cargos administrativos e 11 ocupavam cargos de supervisão, gerência ou direção. Por ocasião do conflito com estrangeiro, dez trabalhavam em grandes empresas (mais de 250 funcionários), três trabalhavam em empresas médias (entre 50 e 250 funcionários) e um em empresa pequena (com menos de 50 funcionários). Por ocasião do conflito com brasileiro, três trabalhavam em cargos administrativos e 11 na supervisão, gerência ou direção. Em 11 casos, trabalhavam em grandes empresas (com mais de 250 funcionários) e em três em empresas médias (entre 50 e 250 funcionários). Esses participantes relataram conflitos com 14 chefes estrangeiros e 14 chefes brasileiros. 


\section{Procedimento de coleta de dados e instrumento de pesquisa}

Os dados foram obtidos por meio de entrevistas semiestruturadas com foco na principal situação de conflito com um estrangeiro e com um brasileiro no ambiente de trabalho. Ao aceitarem participar, assinavam um termo de consentimento informado. Primeiramente, foram obtidos dados sociodemográficos, tais como: idade, sexo, escolaridade e cargo/posição na empresa. Em seguida, foi solicitado ao entrevistado descrever / narrar o principal episódio de conflito vivido com um estrangeiro / brasileiro que tivesse alguma relação com o seu trabalho, considerando os seguintes aspectos: (a) nacionalidade, gênero e idade aproximada da pessoa com a qual o conflito ocorreu; (b) seu cargo ou função; (c) se trabalhava na mesma empresa ou não (cliente ou fornecedor); (d) o contexto no qual o conflito ocorreu; (e) os acontecimentos que antecederam o conflito; (f) o episódio de conflito propriamente dito (o que ocorreu, onde, como, quando e por quê); (g) as consequências pessoais e profissionais do conflito (o desfecho da situação de conflito).

\section{Procedimento de análise de dados e organização do trabalho}

As entrevistas foram gravadas e transcritas, e os resultados obtidos foram interpretados qualitativamente por análise de conteúdo. Consoante Bardin (1979), esse é um método de tratamento e análise de informações, colhidas por meio de técnicas de coleta de dados, e se aplica à análise de textos oriundos de qualquer tipo de comunicação oral. Segundo Minayo (1993), na análise de conteúdo pode-se relacionar os temas emergentes - o que consiste em descobrir os núcleos de sentido que compõem uma comunicação.

A partir de uma análise inicial das respostas, quatro temas foram definidos para discussão mais detalhada: (a) fatores desencadeadores do conflito, com base nas respostas relativas ao contexto no qual o conflito ocorreu e aos acontecimentos que o antecederam; (b) o episódio de conflito propriamente dito; (c) as consequências do conflito, com base em respostas sobre consequências pessoais e profissionais do conflito. Em cada um desses temas, procurou-se identificar categorias que pudessem agrupar os diferentes pontos relatados por sua semelhança, de forma indutiva.

\section{Resultados e discussão}

Os resultados se referem a conflitos entre brasileiros e chefes estrangeiros e brasileiros. Os participantes relataram os fatores desencadeadores de conflitos, o episódio de conflito propriamente dito e suas consequências. As referências às diferenças culturais em torno do conflito são apresentadas em um quarto item.

Os participantes relataram seu relacionamento com 14 chefes estrangeiros de sete diferentes nacionalidades, sendo quatro japoneses, três coreanos, dois franceses, um holandês, um alemão, um chinês e dois norte-americanos. A idade destes variou de 32 a 57 anos. Entre os chefes havia sete gerentes, três diretores, dois consultores internos, um supervisor e um vicepresidente. Os chefes brasileiros incluíam dois amazonenses, nove paulistas, um paraense, um paraibano e um brasileiro de origem italiana. Suas idades variavam de 34 a 60 anos. Um era coordenador, dez eram gerentes e três eram diretores. 


\section{Fatores desencadeadores do conflito}

Os fatores desencadeadores de conflito entre funcionários brasileiros e chefes estrangeiros e brasileiros, associados ao contexto e aos antecedentes do conflito, foram organizados em sete categorias:

(a) Fatores ligados à produtividade e eficiência - No caso de chefes brasileiros, desencadearam conflitos a avaliação de desempenho, dificuldade com prazos, falta de qualidade, perda de produção e questões ou problemas técnicos. No caso de chefes estrangeiros, a ênfase em produtividade dos chefes ou a cobrança de resultados e questões de ordem técnica, incluindo problemas nas ferramentas de trabalho e no seu manuseio, geraram conflitos. Problemas técnicos ou dificuldades com prazos e qualidade foram apontados nas duas situações.

(b) Fatores ligados à metodologia do trabalho e planejamento - No caso de chefes brasileiros, desencadearam conflitos a não execução do procedimento padrão, estratégias para resolução de problemas e problemas no planejamento de projetos (cronograma). No caso dos estrangeiros, a não execução ou cumprimento do procedimento padrão de trabalho e a falta de planejamento para a implementação sistemática de projetos desencadearam conflitos. Em ambos os casos, o não cumprimento do procedimento padrão foi apontado.

(c) Fatores ligados à hierarquia e comando ou liderança - No caso dos chefes brasileiros, os conflitos estavam relacionados a divergência de opiniões, tomada de decisões arbitrárias, conflito na posição hierárquica, abuso de autoridade, ameaça, pressão psicológica e críticas. No caso dos estrangeiros, a estrutura hierárquica confusa, problemas acerca da tomada de decisões e esquiva de responsabilidades, de cumprimento de regras e divergências de opiniões. Em ambos os casos, o processo de tomada de decisão foi mencionado, além de problemas com a hierarquia, pressão e cobrança e relações de poder. No caso da chefia estrangeira, contudo, parece haver uma diferença maior na hierarquia.

(d) Problemas da empresa ou institucionais - Com chefes brasileiros, questões como burocracia, questões financeiras e econômicas, greve, fofoca e problemas na estrutura organizacional geraram as desavenças. No caso de chefes estrangeiros, a má situação financeira e conversas paralelas ao trabalho no ambiente de trabalho deram origem a conflitos. Em ambos os casos, alguns problemas com chefes ou supervisores parecem ter uma dimensão mais global da empresa, como greves, burocracia, questões financeiras ou problemas econômicos e conversas não relacionadas ao serviço.

(e) Problemas de comunicação e relacionamento interpessoal - Em relação aos chefes brasileiros, foram mencionados desentendimentos (criando situações de mal-estar e de perseguição), baixa tolerância a críticas, perseguição e imprevisibilidade. Quanto aos chefes estrangeiros, fatores que desencadearam conflitos foram a falta de compreensão do funcionário local, a má interpretação das atitudes, agressão física e desconfiança. A comunicação entre funcionários brasileiros e chefia estrangeira se tornou um problema por falta de entendimento dos idiomas dos chefes estrangeiros ou por incompreensão das conversas ou mensagens trocadas entre eles. Todos os funcionários afirmaram que essa falta de entendimento foi a causa principal do conflito. As formas de comunicação também se tornaram problema quando as chefias estrangeiras não compreendiam as atitudes dos brasileiros. Apesar de ocorrerem em ambos os casos, os problemas de comunicação e relacionamento interpessoal parecem apresentar maior diversidade quando envolvem chefes estrangeiros, como no caso de má interpretação das atitudes. As dificuldades de comunicação, observadas neste estudo, são encontradas em diversas investigações. Segundo Hamdorf (2003), os encontros interculturais facilmente dão origem a mal-entendidos e comportamentos involuntariamente ofensivos. Choe (2001) ainda aponta diferenças nos hábitos verbais e não verbais e scripts de interação como fontes potenciais de conflitos interculturais. 
(f) Problemas de natureza ética ou moral - No caso de chefes brasileiros, conflitos foram gerados pela presença de diferentes valores éticos ou pela falta de ética, sabotagem, ambição e poder, discriminação e preconceito. Atitudes não éticas diziam respeito aos valores organizacionais para conseguir ganhos secundários, sabotando os funcionários, tomando para si ideias que não eram deles e passavam por cima de todos para conseguir promoções e visibilidade. Discriminação e preconceito causaram dificuldades no convívio com a chefia, visto que era latente a desconfiança no desempenho do funcionário devido a suas origens. No caso de chefes estrangeiros, a falta de ética de ordem fiscal ou trabalhista, demonstração de poder, preconceito e discriminação desencadearam conflitos. Problemas éticos, como discriminação e preconceito, assédio moral, falta de ética e sonegação fiscal, ocorreram nas duas situações, assim como ambição e poder.

A literatura sobre conflitos verticais (entre diferentes níveis hierárquicos) nas organizações, apesar de relativamente restrita (Xin \& Pelled, 2003), aponta para esses conflitos como envolvendo relações de poder (McIntyre, 1991; Hogan, Curphy \& Hogan, 1994), gerando diferentes estilos de conflitos (McIntyre, 1991; Rahim, 1992; Rahim e Buntzman, 1989; McIntyre, 2007). A própria hierarquia pode ser considerada em boa parte como a origem dos conflitos (Rahim, 1986), o que parece ocorrer com os entrevistados. De certa forma, entre os fatores desencadeadores de conflitos, vários podem ser identificados como conflito de papéis (Schaubroeck, Ganster, Sime \& Ditman, 1993). Como investigado por Xin e Pelled (2003), os tipos de conflito nas díades verticais geram um componente emocional (e não apenas em torno da tarefa), o que parece intensificar os conflitos verticais, dificultando o relacionamento entre pessoas em diferentes posições hierárquicas.

\section{Episódio do conflito}

O conflito com chefes estrangeiros e brasileiros mostrou-se mais como um fenômeno relacional do que episódios pontuais. Assim, ao descrever um episódio de conflito, os participantes retomavam os fatores que levaram à sua deflagração e não a um episódio propriamente dito, sendo as descrições muito breves. Ao descrever episódios de conflito com estrangeiros, os participantes mencionaram agressividade verbal e comportamento agressivo, chegando a agressão física. Quanto ao conflito com chefes brasileiros, os participantes não se referiram a agressividade verbal ou física.

O conflito, na maior parte das vezes, deu-se na presença de outros funcionários (11), no caso dos chefes estrangeiros, sendo de modo mais discreto com os chefes brasileiros (em apenas seis dos 14 casos o conflito foi presenciado por terceiros). Em ambos os casos, todos atribuíram o conflito ao chefe ou supervisor.

\section{As consequências do conflito}

Antes do conflito com chefes estrangeiros e brasileiros, a maioria (11) reconheceu a existência de um relacionamento apenas profissional (limitado a um conjunto de interações sociais necessárias para a realização do trabalho). Quanto a chefes estrangeiros, ainda foi indicada a existência de relacionamento social (relacionamento mais amplo do que aquele necessário para a realização das tarefas) e mesmo cordial (relacionamento social mais positivo marcado por maior afetividade e acolhimento). Em um único caso, o participante indicou, antes do conflito, o relacionamento com o chefe como algo motivador para o trabalho. Com chefe brasileiro, dois reconheceram um relacionamento social, um indicou um relacionamento desrespeitoso e outro uma relação conflituosa.

Depois do conflito, os participantes indicaram mudanças no relacionamento para melhor ou pior ou se permaneceu o mesmo. Assim, sete funcionários com chefes estrangeiros e

\section{8}


12 com chefes brasileiros mencionaram um relacionamento apenas profissional após o episódio de conflito. Quanto às consequências do relacionamento para a vida profissional, os dados também sugerem diferenças entre os dois grupos. Vários funcionários com chefes estrangeiros consideraram que o conflito melhorou o entendimento entre as partes (5), o que indica que o conflito nem sempre é percebido como algo negativo. Por outro lado gerou desmotivação e desconfiança. Para alguns participantes, não houve diferença antes nem depois do conflito. No caso de chefes brasileiros, apenas um apontou um lado positivo. Os outros consideraram o relacionamento como desrespeitoso, conflituoso, sem mudança ou desmotivador.

Nesse sentido, as consequências parecem ser mais negativas na relação com brasileiros. Com estrangeiros, as consequências do conflito tinham aspectos positivos e negativos. Do ponto de vista positivo, foram mencionados o crescimento e o amadurecimento profissional, a busca de outros meios para obter ajuda e de qualidade de vida, o respeito mútuo. Do ponto de vista negativo, citaram que houve prejuízos, sem especificarem quais, desequilíbrio e autossabotagem, desconfiança e falta de autonomia. Entre brasileiros e brasileiros, as consequências do conflito foram vistas como predominantemente negativas, como o desrespeito, fofocas, indiferença, sabotagem, descontentamento e ameaça. Como ponto positivo, falaram de ética e amadurecimento profissional. Em poucos casos o conflito não foi visto como algo negativo. Para alguns participantes (6) não houve diferença antes nem depois do conflito, não houve consequências.

Finalmente, entre brasileiros e estrangeiros alguns não teriam o mesmo comportamento (6), mas outros manteriam o mesmo comportamento (8). Por outro lado, entre brasileiros e brasileiros, apenas dois afirmaram que não teriam o mesmo comportamento, mas a maioria (12) se comportaria da mesma forma. Isso também mostra um menor efeito do conflito sobre o comportamento futuro.

\section{Conflito e diferenças culturais}

A maioria dos funcionários com chefes estrangeiros acreditou que o conflito tinha ocorrido por diferenças culturais (10). Com chefes brasileiros, a maioria (9) não atribuiu o conflito a diferenças culturais. Apenas cinco atribuíram o conflito a diferenças culturais. Possivelmente, as diferenças culturais nas relações com chefes brasileiros são devidas ao fato de esses também apresentarem diferenças quanto à formação cultural e educacional, associada à sua origem de diferentes estados do Brasil. Essas diferenças são mais de natureza social, educacional ou pessoal atribuídas à cultura.

As diferenças culturais parecem ser mais diversificadas e intensas nas relações com chefes estrangeiros. Nesse caso, vários aspectos dos conflitos foram atribuídos a diferenças de cultura ou nacionalidade entre funcionários e supervisores, incluindo diferenças pessoais, educacionais e sociais atribuídas à cultura e diferenças na gestão das organizações.

Vários autores (como Ting-Toomey \& Oetzel, 2001) têm indicado a importância de diferentes expectativas quanto ao comportamento apropriado e inapropriado em um conflito intercultural. Os dados obtidos indicam que os brasileiros percebem expectativas equivocadas nos estrangeiros quanto ao desempenho, além de certa desconfiança. Por outro lado, os brasileiros também deixam transparecer expectativas com relação a esses estrangeiros que não são reais.

No primeiro caso (chefes estrangeiros), as diferenças seriam atribuídas à educação diferenciada entre os países, comprometimento diferenciado entre brasileiros e estrangeiros, desconfiança, não assumir culpa, discriminação e preconceito, idioma, arrogância, comportamento agressivo, inflexibilidade. 
No segundo caso (chefes brasileiros), obediência a hierarquia muito forte, concentração das informações, diferenciação entre gêneros (diferenças salariais desrespeitando as leis trabalhistas), burocracia, preocupação com resultados, protecionismo, não adotar as normas do local. Entre brasileiros, apesar de os chefes ou supervisores também terem nascido no mesmo país, ainda assim a questão das diferenças culturais foi apontada. Alguns aspectos dos conflitos foram atribuídos a culturas diferentes entre funcionários e supervisores. Essas divergências são de natureza cultural; conhecimentos culturais; diferenças culturais e educação diferenciada entre os estados e, possivelmente, discriminação e preconceito. Essas divergências são mais de natureza social, educacional ou pessoal atribuídas à cultura.

Assim, diferenças culturais estão presentes em ambos os grupos, mas são mais diversas e intensas entre brasileiros e estrangeiros. Alguns paradoxos precisam de mais investigações. A agressividade está mais presente nos episódios de conflito entre brasileiros e estrangeiros. Por outro lado, os dados sugerem que os conflitos com estrangeiros tenham uma evolução mais positiva, e os brasileiros veem mais consequências positivas nos conflitos com estrangeiros do que com brasileiros. Esses aspectos deveriam ser investigados em maior profundidade. Finalmente, no caso de brasileiros e estrangeiros, a maioria pensa que o conflito poderia ocorrer mesmo entre brasileiros (12). Entre brasileiros e brasileiros, a maioria (8) acha que o conflito aconteceria, mesmo se o chefe fosse estrangeiro.

(g) Diferenças culturais e educação diferenciada - No caso dos chefes brasileiros, tais diferenças foram atribuídas à origem dos chefes (de estados diferentes no Brasil). Há diferentes fatores desencadeadores de conflitos entre funcionários e chefes brasileiros, desde fatores pessoais, atribuídos à empresa até aqueles de ordem cultural, quando os funcionários se referem a diferenças culturais e educação diferenciada entre os estados. Os dados sugerem que o fato de o ambiente de trabalho envolver supervisores de outros estados gera novas possibilidades de conflito interpessoal ou pelo menos outras atribuições de causa para esses conflitos. No caso de chefes estrangeiros, foram consideradas diferenças culturais e educacionais que desencadearam conflitos a diferença na sujeição à hierarquia no Brasil, desconfiança da experiência do funcionário brasileiro, dificuldade na comunicação, falta de confiança, preconceito, expectativas elevadas, entendimento das leis do país, dificuldade de compreensão técnica dos subordinados, preconceito e desconfiança em relação à competência profissional dos subordinados, diferentes valores atribuídos à família e à empresa e comparações entre os dois países.

Diferenças culturais e educacionais aparecem nas duas situações (com chefes brasileiros e estrangeiros), apesar de se manifestarem de modo mais pronunciado e diversificado nas relações com estrangeiros. Alguns elementos parecem estar mais presentes nos problemas com chefes estrangeiros, como a desconfiança. Problemas quanto ao desconhecimento das leis trabalhistas do país, assim como a comparação entre dois países, foram relacionados apenas aos chefes estrangeiros. Alguns fatores são atribuídos somente aos chefes e supervisores estrangeiros, de modo que a diversidade de problemas parece ser maior quando se trata de estrangeiros na chefia.

A desconfiança dos estrangeiros em relação aos brasileiros e no sentido inverso esteve presente, como previsto por Sanchez-Burks, Nisbett e Ybarra (2000), nos relacionamentos entre pessoas de diferentes nacionalidades em organizações. Conforme indicado por SanchezBurks e Mor-Barak (2004), a ênfase no relacionamento ou na tarefa e o emprego de comunicação direta ou indireta representam diferenças culturais no relacionamento interpessoal, aumentando as possibilidades de incompreensões e conflitos, o que foi observado nesta investigação. Possivelmente, os brasileiros percebam a ênfase na tarefa e a comunicação direta dos estrangeiros como algo que dificulta o relacionamento. Atuar com foco no resultado e com respeito às regras e técnicas estipuladas pela organização matriz revela que os chefes estrangeiros seguem diretrizes importadas. 
De modo geral, pode-se atribuir a semelhança entre chefes estrangeiros e brasileiros à própria natureza do sistema capitalista, voltado para a produção, com uma administração rígida em termos hierárquicos. As dificuldades de comunicação também não se restringem às diferenças de idioma. Apontar questões éticas é comum às duas situações. Um ponto interessante é a atribuição (pelo menos de uma parte) dos conflitos a diferenças culturais para chefes brasileiros, assim como para chefes estrangeiros. Contudo, essas diferenças parecem mais fortes quando os chefes são estrangeiros. Isso levanta outro interessante ponto de pesquisa quanto à percepção de diferenças culturais entre chefes brasileiros oriundos de diferentes estados.

A maioria considerou o relacionamento com chefes como algo apenas profissional. $\mathrm{O}$ relacionamento ainda foi visto como social em ambos os casos, e mesmo cordial com os chefes estrangeiros, ou desrespeitoso e conflituoso com os chefes brasileiros, o que sugere que o relacionamento com um chefe estrangeiro não precisa ser necessariamente mais conflituoso que com chefes brasileiros.

Apesar de não ser o objetivo da presente pesquisa, algumas diferenças surgiram entre como gestores brasileiros e estrangeiros negociam conflitos. Assim, apesar de, aparentemente, haver maior agressividade no episódio de conflito, o desfecho parece ser mais positivo com os estrangeiros. Diferenças culturais entre estilos de negociação de conflitos foram investigadas em diversas situações (Boonsathorn, 2007; Posthuma, White, Dworkin, Yánez \& Swift, 2006; Tinsley \& Brett, 2001). Possivelmente, a maior agressividade durante o conflito possa estar relacionada ao uso pelos estrangeiros da comunicação direta, explícita, como estratégia de gestão de conflitos (Brew \& Cairns, 2004).

Conforme Ventorini e Garcia (2004), as similaridades e as diferenças nas características pessoais podem ter efeitos positivos ou negativos sobre os relacionamentos nas organizações, alterando a probabilidade de conflitos ou competição. Possivelmente, as diferenças relacionadas a educação e cultura ajudem a ampliar as possibilidades de conflito entre brasileiros e estrangeiros. Segundo Sanchez-Burks e Mor-Barak (2004), reunir pessoas de diferentes origens é mais suscetível de tornar essas diferenças evidentes.

Entre os problemas apontados nas relações entre brasileiros e estrangeiros estão os preconceitos e a desconfiança, também encontrados em outras investigações (Sanchez-Burks, Blount \& Bartel, 2006). Por outro lado, o relacionamento com estrangeiros apontou mais aspectos positivos do que aquele com outros brasileiros, especialmente quanto às consequências dos conflitos. Os mesmos autores reconheceram que interações interculturais podem promover a criatividade e melhorar a resolução de problemas e o desempenho individual e grupal. Hamdorf (2003) ainda alerta para o risco do aumento de preconceitos e estereótipos a partir de conflitos interculturais, de modo que os conflitos têm um elevado custo psicológico, social e econômico.

Em suma, os conflitos envolvem aspectos imediatos do trabalho, como questões técnicas, revelam tensões ou dificuldades de relacionamento interpessoal entre os funcionários e seus supervisores, incluindo preconceitos, aspectos culturais e educacionais.

\section{Considerações finais}

Os dados obtidos apontam para os dois tópicos apresentados na revisão da literatura. $\bigcirc$ conflito surge como um fator presente nas relações do trabalhador brasileiro tanto com seus compatriotas quanto com pessoas de outros países. De forma repetida, os conflitos narrados sempre ocorreram entre o participante e alguém em uma posição hierárquica superior. 
Tomando-se Hinde (1997) como referencial para o estudo do relacionamento interpessoal, pode-se perceber que o relacionamento entre duas pessoas não se restringe ao contato entre duas pessoas, mas afeta e é afetado por outros níveis de complexidade (como grupos e sociedade). Nesse caso, os relacionamentos e os conflitos neles envolvidos estão relacionados tanto à estrutura sociocultural da organização, com sua hierarquia e cultura, assim quanto a aspectos mais amplos da cultura de outros países. Dessa forma, uma compreensão mais ampla do conflito interpessoal deve levar em conta os grupos nos quais ocorrem e níveis mais amplos, como a cultura de cada país.

Em suma, os conflitos decorrem, em grande parte, em função da estrutura hierárquica e da organização do trabalho, sendo a diferença de nível hierárquico um fator central. Nesse caso, as diferenças culturais parecem aprofundar essas questões e agravar os conflitos, ainda que estes possam ter um desfecho mais positivo.

Compartilhamos a perspectiva de Freitas (2008, 2009) quanto à importância da convivência intercultural nas organizações, à necessidade de construir uma mentalidade intercultural e à possibilidade do aumento da tolerância e do respeito por pessoas, grupos e sociedade de outras origens. Para atingir essas metas, contudo, cremos que os conflitos que acompanham o convívio intercultural devam ser investigados e descritos, como um primeiro passo para a sua superação.

Dois aspectos se destacam nos conflitos investigados: (a) o conflito como um fenômeno entre diferentes níveis hierárquicos em uma organização (com o superior imediato); (b) a influência de fatores culturais nesses conflitos, seja entre brasileiros oriundos de outras regiões do Brasil, seja entre brasileiros e estrangeiros. Segundo os dados obtidos, essas diferenças podem gerar maior diversidade de conflitos entre as pessoas de uma organização. Um ponto que deve ser investigado em maior profundidade são conflitos interculturais entre brasileiros de diferentes estados, entre tradições culturais ligadas a diferentes nações ou regiões.

O estudo avança no conhecimento das relações interpessoais interculturais, especialmente na descrição e categorização dos conflitos existentes entre brasileiros e estrangeiros, comparados com os conflitos entre brasileiros, em uma das regiões com a maior presença de estrangeiros nas organizações no Brasil.

Os conflitos ainda podem ser vistos como oportunidades para o avanço ou reestruturação dos relacionamentos entre as pessoas e da própria organização. Conhecer mais sobre esses conflitos interpessoais e interculturais no Brasil pode contribuir para lidar melhor com esses conflitos para o desenvolvimento pessoal, interpessoal e organizacional de todos aqueles que fazem parte da organização. Mais pesquisas sobre o tema são necessárias, assim como a educação e o treinamento de estrangeiros e brasileiros para melhor convivência entre brasileiros e estrangeiros no mundo do trabalho, apesar das diferenças culturais.

\section{Referências}

Amason, A. C. (1996). Distinguishing the effects of functional and dysfunctional conflict on strategic decision making: resolving a paradox for top management teams. Academy of Management Journal, 39 (1), 123-148.

Bardin, L. (1979). Análise de Conteúdo. Lisboa: Edições 70.

Boonsathorn, W. (2007). Understanding conflict management styles of Thais and Americans in multinational corporations in Thailand. International Journal of Conflict Management, 18 (3), 196-221.

Brew, F. P. \& Cairns, D. R. (2004). Do culture or situational constraints determine choice of direct or indirect styles in intercultural workplace conflicts? International Journal of Intercultural Relations, 28 (5), 331-352. 
Chan, D. K. S. \& Goto, S. G. (2003). Conflict resolution in the culturally diverse workplace: some data from Hong Kong employees. Applied Psychology, 52 (3), 441-460.

Choe, Y. (2001). Intercultural conflict patterns and intercultural training implications for Koreans. Congresso Bianual da World Communication Association, 16. Cantabria, Espanha: World Communication Association.

Coutinho Neto, J. B. (2004). Comportamento estratégico organizacional de uma indústria pertencente ao pólo industrial de Manaus (PIM). Dissertação de Mestrado, Programa de Pós-Graduação em Engenharia de Produção, Universidade Federal de Santa Catarina, Florianópolis.

Eisenhardt, K. M., Kahwajy, J. L. \& Bourgeois, L. J. (1997). How management teams can have a good fight. Harvard Business Review, 75, 77-85.

Euwema, M. C. \& van Emmerik, J. H. (2007). Intercultural competencies and conglomerated conflict behaviors in intercultural conflicts. International Journal of Intercultural Relations, 31 (4), 427-441.

Freitas, M. E. (2000). Como vivem os profissionais expatriados e suas famílias no Brasil? São Paulo: EAESP/FGV.

Freitas, M. E. (2005). Executivos brasileiros expatriados na França. São Paulo: EAESP/FGV.

Freitas, M. E. (2008). O imperativo intercultural na vida e na gestão contemporânea. Organizações Ė Sociedade, 15 (45), 79-89.

Freitas, M. E. (2009). A mobilidade como novo capital simbólico nas organizações ou sejamos Nômades? Organizações Eु Sociedade, 16 (49), 247-264.

Garcia, A. (2005). Relacionamento ionterpessoal: uma área de investigação. In A. Garcia (Org.), Relacionamento interpessoal: olhares diversos (pp. 7-28). Vitória: GM Gráfica e Editora.

Hamdorf, D. (2003). Towards managing diversity: cultural aspects of conflict management in organizations. Conflict $\mathfrak{B}$ Communication Online, 2 (2), 1-22.

Hogan, R., Curphy, G. J. \& Hogan, J. (1994). What we know about leadership: effectiveness and personality. American Psychologist, 49, 493-504.

Holt, J. L. \& DeVore, C. J. (2005). Culture, gender, organizational role, and styles of conflict resolution: a metaanalysis. International Journal of Intercultural Relations, 29 (2), 165-196.

Jehn, K. A. (1995). A multimethod examination of the benefits and detriments of intragroup conflict. Administrative Science Quarterly, 40, 256-282.

Kim, T. Y., Wang, C., Kondo, M. \& Kim, T. H. (2007). Conflict management styles: the differences among the Chinese, Japanese, and Koreans. International Journal of Conflict Management, 18 (1), 23-41.

Loureiro, M. E. M. (2003). O papel estratégico da Zona Franca de Manaus. TEGC Amazônia, 1 (1), 37-41.

Lyra, F. T. (1995). Os incentivos fiscais à indústria da Zona Franca de Manaus: uma avaliação (relatório final). Texto para Discussão - IPEA, 371, 1-170.

McIntyre, S. E. (1991). Conflict management by maleand female managers as reported by self and by male and female subordinates. Tese de Doutorado, Georgia State University, Atlanta.

McIntyre, S. E. (2007). Como as pessoas gerem o conflito nas organizações: estratégias individuais negociais. Análise Psicológica, 2 (25), 295-305.

Minayo, M. C. S. (1993). O desafio do conhecimento: pesquisa qualitativa em saúde. São Paulo: Hucitec.

Nogueira, A. C. F., Sanson, F. \& Pessoa, K. (2007). A expansão urbana e demográfica da cidade de Manaus e seus impactos ambientais. Anais do Simpósio Brasileiro de Sensoriamento Remoto (pp. 5427-5434). Florianópolis: Instituto Nacional de Pesquisas Espaciais.

Oetzel, J., Dhar, S. \& Kirschbaum, K. (2007). Intercultural conflict from a multilevel perspective: trends, possibilities, and future directions. Journal of Intercultural Communication Research, 36 (3), 183-204.

Pelled, L. H., Eisenhardt, K. M. \& Xin, K. R. (1999). Exploring the black box: an analysis of work group diversity, conflict, and performance. Administrative Science Quarterly, 44, 1-28.

Posthuma, R. A., White III, G. O., Dworkin, J. B., Yánez, O. \& Swift, M. S. (2006). Conflict resolution styles between co-workers in US and Mexican cultures. International Journal of Conflict Management, 17 (3), 242 260.

Rahim, M. A. (1986). Referent role and styles of handling interpersonal conflict. The Journal of Social Psychology, $126(1), 79-86$.

Rahim, M. A. (1992). Managing conflict in organizations (2 ${ }^{\text {nd }}$ Ed.). Westport, CT: Praeger Publishers. 
Rahim, M. A. \& Buntzman, G. F. (1989). Supervisory power bases, styles of handling conflict with subordinates, and subordinate compliance and satisfaction. Journal of Psychology, 123 (2), 195-210.

Raider, E., Coleman, S. \& Gerson, J. (2006). Teaching conflict resolution skills in a workshop (pp. 695-725). In E. C. Marcus, M. Deutsch \& P. T. Coleman (Eds.), The handbook of conflict resolution: theory and practice. San Francisco: Jossey Bass.

Sanchez-Burks, J. \& Mor-Barak, M. (2004). Interpersonal relationships in a global work context. In M. Mor Barak (Ed.), Managing diversity in the age of globalization: toward a worldwide inclusive workplace (pp. 114-168). Thousand Oaks: Sage.

Sanchez-Burks, J., Nisbett, R. E. \& Ybarra, O. (2000). Cultural styles, relational schemas and prejudice against outgroups. Journal of Personality and Social Psychology, 79 (2), 174-189.

Sanchez-Burks, J., Blount, S. \& Bartel, C. A. (2006). Fluidity and performance in intercultural workplace interactions: the role of behavioral mirroring and relational attunement. Ross School of Business Paper, 1039.

Santos, C. A. (2002). Movimentos migratórios e redes de indocumentados no Estado do Amazonas: antigos problemas, novas reflexões. XIII Encontro da Associação Brasileira de Estudos Populacionais. Ouro Preto, MG: Associação Brasileira de Estudos Populacionais.

Sato, L. (1999). "Djunta-mon": o processo de construção de organizações cooperativas. Psicologia USP, 10 (2), 219. 225.

Schaubroeck, J., Ganster, D. C., Sime, W. \& Dittman, D. (1993). A field experiment testing supervisory role clarification. Personnel Psychology, 46 (1), 1-25.

Seráfico, J. \& Seráfico, M. (2005). A Zona Franca de Manaus e o capitalismo no Brasil. Estudos Avançados, 19 (54), 99-113.

Sics, B. B. (2002). Desenvolvimento da indústria de componentes para o complexo eletrônico. Estudos e Pesquisas, $37,1-33$

Spicer, A. (1997). Culture and knowledge transfer: conflict in Russian multi-national settings. Proceedings of the Annual Meeting of the Academy of Management, 57 (pp. 194-198). Boston: Academy of Management.

Ting-Toomey, S. \& Oetzel, J. G. (2001). Managing intercultural conflict effectively. Thousand Oaks: Sage.

Ting-Toomey, S. (1988). Intercultural conflicts: a face-negotiation theory. In: Y. Kim \& W. Gudykunst (Eds.), Theories in intercultural communication (pp. 213-235). Newbury Park, CA: Sage.

Ting-Toomey, S. (1999). Communication across cultures. New York: Guilford.

Ting-Toomey, S. (2004). Translating conflict face-negotiation theory into practice. In: D. Landis, J. M Bennett \& M. J Bennett (Eds.), The handbook of intercultural training (pp. 217-248). Thousand Oaks: Sage.

Ting-Toomey, S. (2007). Intercultural conflict training: theory-practice approaches and research challenges. Journal of Intercultural Communication Research, 36 (3), 255-271.

Tinsley, C. H. \& Brett, J. M. (2001). Managing workplace conflict in the United States and Hong Kong. Organizational Behavior and Human Decision Processes, 85 (2), 360-381.

Xin, K. R. \& Pelled, L. H. (2003). Supervisor-subordinate conflict and perceptions of leadership behavior: a field study. The Leadership Quarterly, 14 (1), 25-40.

\section{Endereço para correspondência}

gizadcm@hotmail.com, agnaldo.garcia@pq.cnpq.br 